\title{
O SABER COMO ENSINAR NAS LICENCIATURAS EM CIÊNCIAS DA NATUREZA DO INSTITUTO FEDERAL DE EDUCAÇÃO, CIÊNCIA E TECNOLOGIA DE RONDÔNIA (IFRO)
}

\author{
KNOWING HOW TO TEACH IN THE DEGREE IN NATURE SCIENCES AT THE \\ FEDERAL INSTITUTE OF EDUCATION, SCIENCE AND TECHNOLOGY OF \\ RONDÔNIA (IFRO)
}

\section{SABER ENSEÑAR EN LA LICENCIATURA EN CIENCIAS DE LA NATURALEZA DEL INSTITUTO FEDERAL DE EDUCACIÓN, CIENCIA Y TECNOLOGÍA DE RONDÔNIA (IFRO)}

\section{RESUMO}

Este artigo objetivou compreender os processos do saber como ensinar nos cursos de licenciaturas em Ciências da Natureza do IFRO. Para tanto, analisou-se quatro Projetos Pedagógicos de Cursos, vigentes entre 2010/1 e 2015/2 e ficou evidenciado que o saber como ensinar precisa vincular as práticas pedagógicas desenvolvidas nos espaços escolares com as disciplinas curriculares dos cursos de formação inicial de professores. Tal vinculação possibilitará a interligação dos anseios sociais às necessidades oriundas do enredamento do ambiente educativo formal, que é a escola. A pesquisa também demonstrou que $72,7 \%$ dos Docentes Formadores (DFs) afirmaram que os cursos de licenciaturas em Ciências Biológicas, Física e Química garantiram o saber como ensinar. Ao justificar a afirmação, 39,4\% dos DFs a fizeram apresentando clareza sobre a temática, 27,3\% foram evasivos, $24,3 \%$ não responderam e $9 \%$ atribuíram a responsabilidade desse saber aos DFs licenciados em pedagogia.

Palavras-chave: Licenciatura. Ciências. Natureza. IFRO. Ensinar.

\begin{abstract}
This article aimed to understand the processes of knowing how to teach in IFRO's degree courses in Natural Sciences. To this end, four Pedagogical Course Projects were analyzed, in force between 2010/1 and 2015/2 and showed that knowing how to teach needs to link the pedagogical practices developed in school spaces with the curricular subjects of the initial teacher education courses. This link will enable the connection with social concerns and needs arising from the entanglement of the formal educational environment, which is the school. The survey also showed that $72.7 \%$ of the Faculty Trainers (DFs) stated that the degree courses in Biological Sciences, Physics and Chemistry ensured the knowledge of how to teach. In justifying the statement, $39.4 \%$ of the DFs made it clear
\end{abstract}

\footnotetext{
${ }^{1}$ Doutora em Educação Ciências e Matemática pela Universidade Federal de Mato Grosso (UFMT). Docente Instituto Federal de Educação, Ciência e Tecnologia de Rondônia (IFRO). Porto Velho, Rondônia, Brasil. Rua Monet, 135, apart. 803, Pedrinhas, Porto Velho, Rondônia, Brasil, CEP: 76801-442. E-mail: maranei.rohers@ifro.edu.br

${ }^{2}$ Doutora em Educação pela Universidade de São Paulo (USP). Docente da Universidade Federal de Mato Grosso (UFMT). Cuiabá, Mato Grosso, Brasil. Rua 2, casa nº 98, Bairro Boa Esperança, Cuiabá, Mato Grosso. CEP: 78068-360. E-mail: marponda@uol.com.br
} 
on the subject, $27.3 \%$ were evasive, $24.3 \%$ did not respond and $9 \%$ attributed the responsibility for this knowledge to the DFs licensed in pedagogy.

Keywords: Graduation. Sciences. Nature. IFRO. To teach.

\section{RESUMEN}

Este artículo tuvo como objetivo comprender los procesos de saber enseñar en las carreras de grado en Ciencias Naturales de IFRO. Para ello, se analizaron cuatro Proyectos Pedagógicos de vários cursos vigentes entre 2010/1 y 2015/2, que mostraron que el saber enseñar necesita vincular las prácticas pedagógicas desarrolladas en los espacios escolares con las asignaturas curriculares de los cursos de formación inicial docente. Así, este vínculo permitirá la conexión con las inquietudes y necesidades sociales derivadas del enredo del entorno educativo formal, que es la escuela. La encuesta también mostró que el 72,7\% de los Docentes Formadores (FD) afirmó que las carreras de grado en Ciencias Biológicas, Física y Química aseguraron el conocimiento de la enseñanza. Al justificar la afirmación, el 39,4\% de los FD dejaron claro el tema, el 27,3\% fueron evasivos, el $24,3 \%$ no respondió y el $9 \%$ atribuyó la responsabilidad de este conocimiento a los FD licenciados en pedagogía.

Palabras clave: Graduación. Ciencias. Naturaleza. IFRO. Enseñar.

\section{INTRODUÇÃO}

Esta pesquisa se constitui um recorte de uma investigação de doutorado, que teve como foco os cursos de licenciatura de Ciências da Natureza de quatro campi do Instituto Federal de Educação, Ciência e Tecnologia de Rondônia (IFRO) de Colorado do Oeste, JiParaná, Ariquemes e Porto Velho Calama. Objetivamos compreender os processos do saber como ensinar nos cursos de licenciaturas em Ciências da Natureza do IFRO. Como objetivo específico buscamos identificar elementos nas propostas dos cursos, nas respostas dos Docentes Formadores e Professores Egressos, que relevam o saber como ensinar na formação profissional para a docência. A problemática que orientou este recorte de estudo é "como os cursos de licenciatura em Ciências da Natureza do IFRO garantem o saber como ensinar?".

Saber este que é caracterizado por Lee Shulman (2014) como um conjunto de conhecimentos didático-pedagógicos imprescindíveis à prática docente, assegurado que o ensino "requer habilidades básicas, conhecimento de conteúdo e habilidades pedagógicas gerais". 
Para Gatti e Nunes (2009), o saber como ensinar se institui de conhecimentos que a autora os categoriza como fundamentos teóricos da educação ${ }^{3}$, relativos aos sistemas educacionais ${ }^{4}$ e conhecimentos relativos a modalidades e nível de ensino específicas ${ }^{5}$, vinculados a conteúdos destinados à Educação Básica nos Projetos Pedagógicos dos Cursos (PPC) de Ciências Biológicas, Química e Física.

Com base nesse entendimento, a investigação analisou a visão dos Docentes Formadores (DFs) que lecionam nos cursos de licenciatura em Ciências da Natureza, bem como de todos os acadêmicos, atualmente Professores Egressos (PEs) que cursaram licenciatura em Ciências Biológicas, Física e Química no período de 2010/1 a 2015/2 no IFRO e estão lecionando no Ensino Fundamental e/ou Médio da Educação Básica. Esses períodos letivos coincidiram com o período da formação da primeira turma de licenciados de cada um dos cursos dos campi retromencionados.

A pesquisa foi desenvolvida a partir de uma abordagem qualitativa, com base na análise documental dos PPCs de Ciências Biológicas, Química e Física dos quatro campi e contou com aplicação de um questionário misto a 33 DFs e 05 PEs. Assim, o artigo está organizado em três seções, além da introdução e considerações: a primeira seção versa sobre o referencial teórico a respeito do saber como ensinar, especificamente no contexto das licenciaturas em Ciências da Natureza; a segunda seção apresenta a metodologia e registra também o caminho percorrido no desenvolvimento desta investigação; a terceira seção expõe os resultados do estudo realizado com base nas três visões relacionadas ao saber: 1) o saber como ensinar previstas nos PPCs de licenciaturas em Ciências da Natureza do IFRO; 2) a visão dos Docentes Formadores sobre o saber como ensinar nas licenciaturas em Ciências da Natureza do IFRO; 3) a visão dos Professores Egressos pertinentes ao saber como ensinar nas licenciaturas em Ciências da Natureza do IFRO.

Entre os principais teóricos estudados estão Shulman (1986), García (1995), Gauthier et al. (1998), Pimenta (1999), Imbernón (2011) e Tardif (2014).

3 Nessa categoria, estão presentes as disciplinas como Antropologia, Estatística, História, Psicologia, Sociologia, entre outras.

4 Nesse agrupamento, estão presentes, por exemplo, Financiamento da Educação Básica no Brasil, Elaboração de Projetos Pedagógicos, Função do Diretor, Ética Profissional, entre outros.

5 Nessa categoria, estão presentes nível de educação infantil, nível de educação especial, nível de educação de jovens e adultos, entre outros. (GATTI E NUNES, 2009, p. 19-20). 


\section{REFERENCIAL TEÓRICO}

O saber como ensinar requer a compreensão de que as discussões pertinentes à docência transcorrem desde o início da formação inicial de professores até a conclusão da carreira docente. Assim, buscar a compreensão da conjuntura que envolve a formação de professores se constitui em refletir sobre a própria experiência enquanto aluno, pensar sobre a vinculação que a sociedade possui com a educação, ponderar sobre os aprendizados na profissão de professor, particularmente, no âmbito do espaço escolar, assim como no desdobramento que originará para a vida em si.

De acordo com García (2009, p.9), “[...] o desenvolvimento profissional docente pode ser entendido como uma atitude permanente de indagação, de formulação de questões e procura de soluções". Nesse sentido, o saber como ensinar, matéria inerente à área da formação de professores, tem sido debatida por pesquisadores que, explicitamente, apresentam contribuições para a proposição de leis, princípios e instruções sobre as licenciaturas.

Em se tratando das legislações que abordam a respeito do saber como ensinar, a Resolução CNE/CP n. ${ }^{\circ}$ 02/2015 em seu art. 12, dispõe acerca dos "núcleos de formação", que se constituem como guias para a preparação e ampliação dos saberes difundidos nos cursos de licenciaturas. Tais núcleos são:

\section{Núcleo de estudos de formação geral, das áreas específicas e interdisciplinares, e do campo educacional, seus fundamentos e metodologias, e das diversas realidades educacionais; II. Núcleo de aprofundamento e diversificação de estudos das áreas de atuação profissional, incluindo os conteúdos específicos e pedagógicos e a pesquisa priorizadas pelo projeto pedagógico das instituições, em sintonia com os sistemas de ensino; e III. Núcleo de estudos integradores para enriquecimento curricular-(BRASIL-CNE-CP, 2015, p. 8-11).}

No decorrer das décadas, diversos pesquisadores têm cooperado com o saber como ensinar nos cursos de formação inicial de professores, dentre eles, Shulman (1986), García (1995), Gauthier et al. (1998), Pimenta (1999), Imbernón (2011), Tardif (2014). Pode-se constatar que tais autores, em diversos pontos, convergem entre si ao argumentarem sobre a influência que os núcleos de formação exercem sobre licenciaturas.

Com relação ao saber como ensinar, Shulman (1986), ao tratar do conhecimento pedagógico do conteúdo, afirma que este é constituído de um novo tipo de conhecimento, que se constrói permanentemente pelo professor, no processo do ensino do referido conteúdo. Tal conhecimento é abundante e aprimorado na medida em que são combinados 
com outros tipos de conhecimentos, que podem ser de ordem didática (formas, fazer), metodológica (como fazer), recursos (uma ferramenta). Nesse processo, o professor tem a oportunidade de construir um novo tipo de conhecimento pertinente à área específica, pois este, é ampliado e engrandecido pelos demais conhecimentos. Na prática, o docente adota procedimentos de "analogias, as mais poderosas, ilustrações, exemplos, explanações e demonstrações" (SHULMAN, 1986, p. 9).

Para García (1995), o saber como ensinar está relacionado àquilo que versa sobre o conhecimento didático do conteúdo, representado pela articulação entre o conhecimento da matéria que será lecionada e o conhecimento pedagógico e didático concernente a como ensiná-la. Tal conhecimento, didático do conteúdo, nos remete a uma discussão sobre a maneira de constituir e de retratar o conhecimento por meio de correlações e símbolos. Nesse aspecto, García (2009, p. 120) aponta a "necessidade de que os professores em formação adquiram um conhecimento experiente do conteúdo a ser lecionado, para que possam desenvolver um ensino que propicie a compreensão dos alunos".

Pimenta (1999), refere-se aos saberes pedagógicos como aqueles que abordam o como ensinar. Ao tratar desse saber, engloba não apenas conceitos da didática, mas também conhecimento para ensinar. E, sendo assim, faz-se necessário a experiência, os conhecimentos específicos, assim como os saberes pedagógicos e didáticos.

O saber como ensinar, para Imbernón (2011, p. 36), encontra-se no conhecimento pedagógico especializado. Para o autor, tal conhecimento "se legitima na prática e [...] reside nos procedimentos de transmissão, reunindo características específicas como a complexidade, a acessibilidade, a observabilidade e a utilidade social”.

Gauthier discute o conhecimento pertinente ao saber como ensinar, por meio dos

saberes disciplinares (a matéria), saberes curriculares (o programa), saberes das ciências da educação (na formação ou em seu trabalho), saberes da tradição pedagógica (o uso), saberes experiências (jurisprudência particular), saberes da ação pedagógica (o repertório de conhecimentos do ensino ou da jurisprudência pública validada) (GAUTHIER ET AL. 1998, p. 28)

Tardif sistematiza os saberes dos professores e as fontes sociais de aquisição em

saberes pessoais dos professores (a família, o ambiente de vida, a educação no sentido lato, etc.), saberes provenientes da formação escolar anterior (a escola primária e secundária, os estudos de pós-secundário não especializados, etc), saberes provenientes da formação profissional para o magistério (os estabelecimentos de formação de professores, os estágios, os curso de reciclagem, etc.), saberes provenientes dos programas e livros didáticos usados no trabalho (a 
utilização das ferramentas dos professores: programas, livros didáticos, cadernos de exercícios, fichas, etc), saberes provenientes de sua própria experiência na profissão, na sala de aula e na escola (a prática do ofício na escola, na sala de aula, a experiências dos pares, etc. (TARDIF, 2002, p. 63)

Segundo Nóvoa (1997, p. 25), “a formação não se constrói por acumulação (de cursos, de conhecimentos ou técnicas), mas sim através de um trabalho de refletividade crítica sobre as práticas e de (re)construção permanente de uma identidade pessoal [...]". Neste sentido, ao docente refletir a respeito da sua práxis, registrar suas experiências e disseminar suas produções permite o autodesenvolvimento como procedimento de formação que instiga o processo de ensinar.

Nesse sentido, observa-se a demanda de um conhecimento em que predomine a polivalência e que estes conhecimentos empreendam intervenção no processo de ensino e aprendizagem do aluno.

Para Barbosa (2012, p. 66) "um educador em Ciências Naturais, que compreende o conhecimento escolar organizado em grandes áreas do conhecimento, como propõem as diretrizes curriculares para a Educação Básica” precisa agregar novos conhecimentos e vivências profissionais durante o curso de formação inicial de professores, portanto, necessita ser um professor bem formado. Sendo assim, esse professor necessita também desenvolver na sua formação os componentes para implementação da profissão, particularmente, em prol dos estudantes que apresentam maior vulnerabilidade social.

\section{METODOLOGIA}

Por meio deste artigo, propusemo-nos a compreender de que forma os cursos de licenciatura em Ciências da Natureza do IFRO consideram o saber como ensinar. Dessa forma, procuramos os fundamentos essenciais para a implementação deste estudo na abordagem qualitativa.

De acordo com Flick

[...] os métodos qualitativos consideram a comunicação do pesquisador em campo como parte explícita da produção de conhecimento, em vez de simplesmente encará-la como uma variável a interferir no processo. A subjetividade do pesquisador, bem como daqueles que estão sendo pesquisados, torna-se parte do processo de pesquisa. As reflexões dos pesquisadores sobre suas próprias atitudes e observações em campo, suas impressões, irritações e, sentimentos, etc., tornamse dados em si mesmos, constituindo parte da interpretação e são, portanto, documentadas em diários de pesquisa ou em protocolos de contexto (FLICK, 2009, p. 25) 
Aqui, a abordagem qualitativa se assinala pela procura do aprofundamento da ação docente por meio da flexibilidade e da reflexão dos dados produzidos por meio da pesquisa, importantes para o entendimento da própria prática docente com vistas ao processo do saber como ensinar nos cursos de licenciaturas do IFRO.

Esta investigação, de caráter qualitativo, também contou com pesquisa documental, e aplicação de questionário misto para 33 Docentes Formadores (DFs) e 05 Professores Egressos (PEs) dos cursos de licenciatura em Ciências Biológicas (campi de Colorado do Oeste e Ariquemes), em Química (campus de Ji-Paraná) e em Física (campus de Porto Velho Calama) do IFRO. Com isso, desenvolvemos uma análise documental com a finalidade de entendermos de que maneira os cursos investigados consideram o saber como ensinar e conseguirmos respostas à questão "como os cursos de licenciatura em Ciências da Natureza do IFRO garantem o saber como ensinar?".

Para Gil (2010, p. 66), na pesquisa documental, "as fontes documentais são muito mais numerosas e diversificadas, já que qualquer elemento portador de dados pode ser considerado documento". Para tanto, o estudo foi desenvolvido a partir da análise de documentos e Projetos Pedagógicos dos Cursos (PPCs), os quais se constituíram como fontes primárias, portanto esta pesquisa é designada como documental. Analisamos as disciplinas propostas às matérias dos conteúdos denominados como didático-pedagógicos. Dessa maneira, em nossa busca, a pesquisa documental foi indispensável para obtermos os dados e, assim, abarcarmos como os cursos de licenciaturas em Ciências da Natureza estruturam as disciplinas que versam dos saberes relacionados ao como ensinar, no decorrer da formação inicial de professores.

A escolha da aplicação de questionários mistos aos DFs e aos PEs, se respaldou também nas definições de Gil (2019, p. 128), ao afirmar que a "investigação composta por um número mais ou menos elevado de questões apresentadas por escrito às pessoas, com objetivo de obter conhecimento de opiniões, crenças, sentimentos, interesses, expectativas, situações vivenciadas etc”, pois, o questionário respondia as necessidades desta pesquisa.

Quando da realização da pesquisa de doutorado, após a leitura dos PPCs e a aplicação dos questionários aos DFs e PEs, a discussão do saber com ensinar foi efetivada a partir do eixo denominado "saber o que e como ensinar". O referido eixo possibilitou suposições, esclarecimentos e a instituição de correlações com a literatura da área de 
formação de professores, dissociando, concomitantemente, as incertezas e potencializando a condução explicativa da compreensão dos dados.

Nesse eixo, organizamos e analisamos as disciplinas que, compreendidas nos PPCs, versam sobre os conteúdos didático-pedagógicos dos cursos pesquisados. Ponderamos, ainda, sobre visão dos Docentes Formadores e Professores Egressos a respeito do saber como ensinar.

Para o tratamento dos dados produzidos a partir dos questionários, nos ancoramos na análise do conteúdo fundamentada em Bardin (1977, p. 42), pois segundo a autora é

\begin{abstract}
Um conjunto de técnicas de análise das comunicações, visando obter, por meios de procedimento sistemáticos e objetivos de descrição do conteúdo das mensagens, indicadores (quantitativos ou não) que permitam a inferência de conhecimentos relativos as condições de produção/recepção (variáveis inferidas) destas mensagens. (BARDIN, 1977, p. 42)
\end{abstract}

Desse modo, ao optarmos pela análise do conteúdo, alude que demos ênfase nas significações (conteúdo), ou seja, buscamos compreender o que está por trás das palavras. Nessa perspectiva, organizamos as ações em três fases:

1) Pré-Análise: (Fase de organização) - nesta fase, cuja incumbência foi a opção dos documentos que ficariam na análise, organizamos o material considerando o problema de pesquisa;

2) A Exploração do Material: nesta fase, selecionamos os materiais que seriam analisados. É uma etapa que versa "essencialmente em operações de codificação, decomposição ou enumeração, em função de regras previamente formuladas" pelo pesquisador (BARDIN 2011, p. 131). Após a exploração do material, definimos os eixos, assim, "realizando o reagrupamento por analogia por meio de critérios definidos previamente no sentido de propiciar a realização da inferência" (BARDIN, 2016, p.119);

3) Tratamento dos Resultados, a inferência e a interpretação: fase em que analisamos os dados e comparamos com o material e o tipo de inferências obtida.

Após os procedimentos de tratamento de dados, com os resultados, obteve-se quatro eixos de análise, pertinentes às Licenciaturas de Ciências da Natureza do IFRO, dos quais discutimos neste artigo, apenas, o como ensinar.

\title{
4 ANÁLISE E RESULTADOS
}


Apresentamos os resultados da pesquisa por meio de três seções, as quais versam sobre os cursos de licenciatura de Ciências da Natureza do IFRO. A primeira trata dos PPCs analisados, a segunda exibe a visão dos Docentes Formadores (DFs) sobre o saber como ensinar, sendo fragmentada em quatro subseções, e a terceira mostra a visão dos Professores Egressos (PEs), também com relação ao referido saber.

\subsection{O saber como ensinar nos Projetos Pedagógicos dos Cursos de licenciatura em} Ciências da Natureza

Com a finalidade de compreender de que maneira os cursos de licenciatura em Ciências da Natureza do IFRO desenvolvem o saber como ensinar, analisamos o currículo nos PPCs dos cursos investigados, com base nas diretrizes curriculares nacionais para as licenciaturas em Ciências Biológicas, Química e Física. Os cursos analisados possuem entre 14 a 16 disciplinas com enfoque no saber como ensinar, e envolve os anos letivos de 2010/1 a 2015/2, conforme organização a seguir:

Licenciatura em Ciências Biológica: 1. Didática Geral, 2. Oficina de Material Pedagógico, 3. Educação Ambiental, 4. Psicologia da Educação, 5. Sociologia da Educação, 6. Educação Inclusiva, 7. Políticas Públicas e Educação, 8. Filosofia da Educação e Ética Profissional, 9. Libras, 10. História da Educação (450 horas). 11. Metodologia do Ensino de Ciências I, 12. Metodologia do Ensino de Ciências II, 13. Informática Aplicada ao Ensino de Biologia, 14. Metodologia do Ensino da EJA, 15. Metodologia do Ensino da Biologia I, 16. Metodologia do Ensino da Biologia II (332 horas) (IFRO, 2012b, p. 24-25; 2012c, p. 25-27).

Licenciatura em Química: 1. Cultura, Ambiente E Educação, 2. Informática Aplicada A Educação, 3. Políticas Pública em Educação, 4. Psicologia da Educação, 5. Didática Geral, 6. Fundamentos Sociológicos e Filosóficos da Educação, 7. Avaliação da Aprendizagem, 8. Libras, 9. Educação Ambiental, 10. Educação Inclusiva (580 horas). 11. Metodologia do Ensino de Ciências I, 12. Metodologia do Ensino de Ciências II, 13. Metodologia do Ensino de Química, 14. Informática Aplicada ao Ensino da Química (340 horas) (IFRO, 2009 p. 15-16).

Licenciatura em Física: 1. Fundamentos Históricos e Filosóficos da Educação, 2. Legislação Educacional, 3. Didática Geral, 4. Psicologia da Educação, 5. Sociologia da Educação, 6. Avaliação da Aprendizagem, 7. Educação Inclusiva, 8. Libras, 9. Gestão e Políticas Educacionais (640 horas). 10. Informática Aplicada ao Ensino da Física, 11. Metodologia do Ensino da Física I, 12. Metodologia do Ensino da Física II, 13. Mídias Educacionais Aplicadas à Física, 14. Metodologia do Ensino da Física III, 15. Metodologia do Ensino da EJA, 16. Metodologia do Ensino da Física IV (440 horas) (IFRO, 2012, p. 23-24). 
Os três cursos de licenciatura na área de Ciências da Natureza do IFRO atendem o que a legislação estabelece referente à carga horária destinada às disciplinas sobre o como ensinar, observando que deve ser no mínimo 1/5 do total da carga horária dos cursos de Ciências Biológicas, Química e Física de acordo com a Resolução CNE/CP no 1/2002, em que no art. $11 \S$ único (CONSELHO..., 2002) é mencionado que devem ser ofertadas desde o primeiro período dos referidos cursos.

O conjunto de disciplinas didático-pedagógicas, integrantes dos PPCs dos cursos de licenciaturas em Ciências da Natureza pode orientar um processo de ensino e aprendizagem que propicia uma base teórica interligada à atuação prática, que proveja aos licenciandos uma práxis educacional sólida. São disciplinas que possibilitam aos licenciandos se apropriar de conhecimentos que levem ao planejamento, ao estabelecimento de metas e instrumentos de maneira que seja evitado o improviso, o praticismo amparado especificamente na experiência. Nesse contexto, faz-se necessário que os licenciandos tenham "[...] domínio das bases teóricas científicas e tecnológicas e sua articulação com as exigências concretas de ensino" (LIBÂNEO, 2013, p. 28). Dessa forma, os licenciandos têm a possibilidade de aperfeiçoar a sua prática em sala de aula e lapidar a qualidade para lecionar.

Também, as disciplinas didático-pedagógicas oportunizam os estudos sobre o saber como ensinar, sistematizando e organizando processos que possam resultar em apropriações de conhecimentos pertinentes à educação. Esses conhecimentos perpassam pelos objetivos, conteúdos, organização de sala de aula, métodos para assegurar o ensino e a aprendizagem, possibilitando confiança ao futuro professor, na condução do trabalho junto as distintas modalidades e níveis que compõem a Educação Básica. A título de exemplo, na ementa de Didática Geral, constante dos PPCs dos cursos de licenciaturas de Ciências da Natureza do IFRO está posta a relação entre ensino e pesquisa, práxis, currículo, planejamento, avaliação e projetos interdisciplinares.

\subsection{A visão dos docentes formadores a respeito do saber o que ensinar nas licenciaturas em Ciências da Natureza do IFRO}

No que se refere à visão dos 33 Docentes Formadores (DFs) a respeito da garantia do saber como ensinar, com base nas distintas disciplinas oferecidas no decorrer dos cursos de 
licenciaturas, os professores registram opiniões diversas em cada um dos quatro campus, assim como também é distinta as opiniões de certo quantitativo de docentes de um mesmo curso. A seguir, apresentamos as análises dessas visões. De maneira a assegurar o anonimato dos DFs, os quais são identificados aqui com um número de 01 a 33 - DF 1, DF 2, DF 3, etc.

4.2.1 Docentes Formadores do Curso de Licenciatura em Ciências Biológicas do IFRO do Campus de Colorado do Oeste

No que tange aos resultados referentes ao saber como ensinar, dos oito DFs do campus de Colorado do Oeste, sete $(01,02,03,05,06,07$ e 08) afirmaram que, "sim", o curso contempla o saber como ensinar e um respondeu que "em parte" DF 04. Os DFs 01, 02, 03 ,05, 06, 07 e 08, que registraram sim, justificaram: O DF 01, em sua justificativa, afirmou que "Conta o próprio modelo adotado no colegiado. Modelo de orientação para o estágio, plano de aula, o que tá envolvido dentro do plano de aula. Tem na teoria, nas disciplinas específicas, no estágio todos os professores que atuam no curso vão orientar na mesma perspectiva. O que se poderia ampliar seria a discussão do ensinar na perspectiva da liberdade". Já o DF 02 não apresentou justificativa. O DF 03 afirmou que "[...] os professores que lecionam as disciplinas pedagógicas são preparados e realizam bem seus trabalhos, tanto de modo teórico como prático". O DF 04, que respondeu "em parte", expondo uma justificativa distinta e com elementos estruturantes de política pública educacional, mencionou que "[...] há muito o que melhorar na formação oferecida, em relação aos conteúdos didáticos, específicos, métodos e práticas mais aplicáveis ao ensino básico, visto que os alunos, nem sempre têm um comportamentos adequado em relação ao estudo, à estrutura física da escola, laboratórios de ciências e de informática que funcionem, além de uma carga horária que dificilmente permite ao docente um planejamento em horário de trabalho". O DF 05, relatou: “[...] baseado naquilo que vejo os alunos apresentarem, eles estão conseguindo construir conhecimentos didáticos suficientes para iniciarem suas carreiras". Os DFs 06 e 07 não apresentaram justificativas. O DF 08 registrou que "Trabalho com metodologia e também com didática e o foco principal no trabalho são os dois pilares da educação: 'saber, e saber fazer', considerando dois grandes problemas da educação escolar: 'como os alunos aprendem e como podem demonstrar o 
que aprenderam'. Baseados nestas premissas, buscamos desenvolver um trabalho que fomente nos alunos do curso uma consciência crítica que os torne professores pesquisadores de métodos facilitadores da aprendizagem".

Assim, concluímos que oito, isto é, $87,5 \%$ dos DFs afirmaram que "o curso de licenciatura em Ciências Biológicas do campus Colorado do Oeste garantiu os conhecimentos didático-pedagógicos vinculados ao saber como ensinar". Contudo, dos $100 \%$ dos DFs, somente $37,5 \%$ justificaram suas respostas a respeito dos conhecimentos do saber como ensinar de forma clara, $12,5 \%$ foram evasivos, $37,5 \%$ não responderam e $12,5 \%$ atribuíram ao pedagogo o encargo deste saber.

Isso pode ocorrer, muitas vezes, por conta da organização segmentada presente nos cursos de formação de professores, aspecto, também observado nos estudos realizados por Gatti e Nunes (2009), ao analisarem o currículo desenvolvido nos cursos de formação de professores uma característica fragmentária, com um conjunto de disciplinas bastante disperso. As autoras afirmam que "Isto se confirma quando se examina o conjunto de disciplinas em cada curso, por semestre e em tempo sequencial, em que, via de regra, não se observam articulações curriculares entre as disciplinas” (GATTI; NUNES, 2009, p. 22).

\subsubsection{Docentes Formadores do curso de Licenciatura em Química do IFRO do campus de Ji-Paraná}

Com relação ao campus de Ji-Paraná, dos nove Docentes Formadores (DFs), três (09, 14 e 17) afirmaram que, "em parte, o curso garante 'do saber como ensinar"”, e seis $(10,11$, $12,13,15$ e 16) responderam "sim". Os três DFs $(09,14$ e 17) afirmaram que, "em parte, o curso assegura o saber como ensinar", justificando da seguinte maneira: DF 09 "[...] havia e possivelmente exista uma carência demasiada a nível nacional de didáticas específicas para o ensino de Química aos surdos [...]". O DF 14 foi evasivo: "Na época que lecionei havia muitas pessoas longe da sala de aula havia anos. As primeiras turmas apresentavam um baixo índice de leitura e interpretação". O DF 17 argumenta que "sempre ficam lacunas quanto a conteúdos e atividades práticas a serem feitas durante a formação do licenciando. As necessidades mudam muito e nem sempre temos tempo e flexibilidade para atender as mudanças que ocorrem ao longo do curso". 
Os seis que responderam "sim" à questão em pauta, apresentaram as justificativas: DF 10 "O curso oferece domínio, principalmente durante o estágio, o aluno/professor é tratado para que suas deficiências sejam sanadas durante o processo”. O DF 11 observou que "[...] há políticas públicas que permitem essa situação, como o Programa Institucional de Bolsa de Iniciação à Docência - PIBID". O DF 12 informou "A partir da disciplina que ministro, que é metodologia de pesquisa". O DF 13 destacou que "Como ele [o curso] tem as disciplinas destinadas para esse conhecimento, teoricamente foram oportunizadas as condições necessárias para ele aprender". Os DFs 15 e 16 não apresentaram justificativas.

Das respostas dos DFs do curso de Licenciatura em Química, temos três que merecem destaque. A primeira, versa sobre a preocupação com o processo de inclusão, mais especificamente o atendimento ao licenciando surdo, o que é pertinente, pois, gradativamente, os estudantes surdos têm adentrado os diversos níveis e modalidade de ensino. Contudo, nem sempre a instituição, assim como os professores, apresenta as condições para atender esse público, seja no que tange ao domínio da Língua 1 (Língua Brasileira de Sinais - LIBRAS) destes estudantes, seja no que diz respeito à infraestrutura, equipamentos, recursos didáticos ou, ainda, no que se refere ao método de ensino.

Nas investigações de Mantoan (2003) uma escola inclusiva precede ampliação célere dos projetos comprometidos de transformação da instituição de ensino, para responder adequadamente aos tempos contemporâneos, em que a inclusão seja viabilidade de direito e de fato. Para tanto, segundo Mantoan (2003, p. 8), se faz necessário ressignificar o "papel da escola com professores, pais, comunidades interessadas e instalando, no seu cotidiano, formas mais solidárias e plurais de convivência".

Laplane (2004), referindo-se ao contexto social econômico mundial e como este provoca diferenças sociais, afirma que a implementação de políticas públicas inclusivas se tornou um amplo desafio em razão das fragilidades presentes quando se trata da escola inclusiva. Mesmo havendo discurso em defesa de políticas inclusivas, estas não têm se apresentado eficientes o bastante.

Entre as fragilidades, Laplane aponta que

caracterizada por classes superlotadas, instalações físicas insuficientes, quadros docentes cuja formação deixa a desejar. Essas condições de existência do sistema educacional põem em questão a própria ideia de inclusão como política que, simplesmente, propõe a inserção dos alunos nos contextos escolares presentes. Assim, o discurso mais corrente da inclusão a circunscreve no âmbito da educação formal, ignorando as relações desta com outras instituições sociais, apagando 
tensões e contradições nas quais se insere a política inclusiva, compreendida de forma mais ampla (LAPLANE apud LACERDA, 2006, p. 168).

Seja pelas razões expostas por Laplane ou pelos motivos mencionados pelo DF 09 "[...] havia e possivelmente exista uma carência demasiada a nível nacional de didáticas específicas para o ensino de Química aos surdos [...]", superar as fragilidades se constitui indispensável no processo de inclusão.

A segunda resposta que requer atenção, diz respeito às dificuldades de leitura e interpretação dos acadêmicos de licenciatura (DF 14). Tais limitações também são apontadas nos resultados das avaliações em larga escala, sobre leitura, matemática e ciências do Programa Internacional de Avaliação de Estudantes (PISA), destinadas a estudantes de 15 anos, nascidos em 2002 e matriculados a partir do $7^{\circ}$ ano do Ensino Fundamental. Em se tratando de leitura, o Brasil ocupa o $76^{\circ}$ lugar no ranking no PISA 2015 (ORGANIZAÇÃO..., 2015).

Amaral (2010, p. 116) colabora com a pesquisa sobre a análise que o professor do Ensino Médio faz a respeito da leitura e da escrita dos alunos, nesse nível de ensino, ao registrar "[...] que o professor de física menciona as dificuldades de leitura dos alunos relacionadas a símbolos, gráficos etc. e a fala da professora de geografia, evidenciando a importância da imagem para a compreensão do texto escrito", isto é, influencia em outras configurações de linguagem. Em relação à contribuição de Silva (2016, p. 193) se caracteriza na medida em que os "[...] professores comprovam por meio das atividades escritas e dos resultados das avaliações que o conteúdo específico da disciplina não tem sido aprendido pelos alunos graças, em boa parte, às dificuldades com leitura e escrita”. Essa comprovação ocorreu junto aos estudantes dos anos finais do ensino fundamental.

Tal situação é procedente, pois a medida em que não se tem uma formação sólida, que garanta os conhecimentos profissionais para a docência, possivelmente, isto refletirá no trabalho do professor na Educação Básica, que, por sua vez, também se fará presente no ensino superior, ou seja, se constitui como algo cíclico. O que se questiona é como e quando vamos conseguir quebrar essa sucessão de limitações no ensino e na aprendizagem?

A terceira situação refere-se ao Programa Institucional de Bolsa de Iniciação à Docência (PIBID) e ao Estágio Curricular Supervisionado serem reconhecidos pelos DFs 10 e 11 como espaços de oportunidades de aplicação do saber como ensinar. Contudo, cabe salientar que o PIBID geralmente não conta com a participação de todos os licenciados (GASPAR, 2017), além de ser um programa. Portanto, tem início, mas não há garantia de 
continuidade. Nesse contexto, o PIBID se apresenta mais como um paliativo tanto para os licenciandos (participação opcional), quanto para os alunos do Ensino Fundamental e Médio, em razão da possível descontinuidade do trabalho desenvolvido pelos licenciandos, em razão de não ter garantia como política pública.

Gaspar (2017), em sua pesquisa sobre o PIBID e suas repercussões na perspectiva de seus atores, concluiu que o programa se estabeleceu como lugar de experiência do aprendizado como docente e refletiu na formação profissional para a docência no curso de licenciatura, visto que proporcionou, aos licenciandos participantes, a implementação de subprojetos nas instituições de ensino fundamental e médio. Proporcionou, ainda, a aproximação do fazer do professor. Gaspar (2017) também afirma ter diminuído a distância entre a Instituição de Ensino Formadora e a escola pública parceira e que esse Programa favoreceu o aluno da Educação Básica na medida em que se inclui outros e novos métodos, procedimentos para ensinar, assim como recursos didáticos. Apesar disso, a autora ressalta que tais transformações ficaram limitadas aqueles alunos do ensino fundamental e médio, cujo professor desempenhava a função de supervisor no PIBID, ou seja, um quantitativo reduzido de alunos, pois nem sempre numa escola todos os professores e alunos participam desse Programa.

Com relação ao estágio supervisionado, se constituir um espaço de vivência do saber como ensinar (DF 10), este começa a ser desenvolvido no quinto período (CONSELHODCN, 2002a), isto é, quando resta metade da carga horária para conclusão da licenciatura, quer dizer, há certa adversidade para executar o que está proposto na Diretrizes Curriculares Nacionais (DCN), para que o licenciando no exercício do estágio não apresente dificuldade sobre os conhecimentos específicos, assim como os didático-pedagógicos.

Entretanto, cabe salientar que mesmo que $66,6 \%$ dos DFs afirmando que o curso de licenciatura em Química do IFRO garantiu o conhecimento do saber como ensinar, a maioria dos DFs em suas justificativas não o evidenciou, pois dos $100 \%$ dos DFs nove, apenas $11,1 \%$, justificaram suas respostas a respeito dos conhecimentos do saber como ensinar claramente. Desse quantitativo, 55,5\% apresentaram respostas evasivas, $22,2 \%$ não responderam e 11,1\% atribuíram ao pedagogo a responsabilidade desse saber.

Essa realidade nos faz aferir que por mais que os cursos de licenciatura em Ciências da Natureza do IFRO dispõem de aspectos que garantem esse saber como ensinar, existe 
ainda a necessidade de que os estudantes desenvolvam habilidades para tal ação, para que, desse modo, o processo seja fato exitoso. Para Libâneo

Não se trata mais de passar conhecimentos, mas de desenvolver nos alunos capacidades e habilidades mentais referentes a esses conhecimentos. Está sendo requerido dos professores que dominem os conteúdos, mas, especialmente, o modo de pensar, raciocinar e atuar próprio de cada disciplina, dominar o produto junto com o processo de investigação próprio de cada disciplina (LIBÂNEO, 2006, p. 861).

Isso exigirá dos DFs a iniciativa de retomarem seus conhecimentos sobre o saber como ensinar, para proporcionar ao licenciando outras oportunidades de aprendizagem que ampliem e fortaleçam os saberes didático-pedagógicos.

\subsubsection{Docentes Formadores do curso de Licenciatura em Ciências Biológicas do IFRO do} campus de Ariquemes

Dos sete Docentes Formadores (DFs) do IFRO do campus de Ariquemes, três dos professores, (DFs 18, 22 e 23), afirmaram que, "em parte, o curso garantiu o saber o que ensinar" e quatro (DFs 19, 20, 21 e 24) responderam que "sim". As justificativas dos Docentes Formadores que responderam "em parte" foram: O DF 18 relatou que " $O$ problema não está nos conteúdos e sim na postura como são aplicados". O DF 22 mencionou que "O fato se deve a uma maior ênfase na pesquisa e conteúdos técnicos do que nos processos de ensino-aprendizagem". O DF 23 registrou que "A implantação das licenciaturas ainda está em fase de aprimoramento".

No que tange as justificativas dos DFs que responderam que os conhecimentos sobre o saber como ensinar foram garantidos durante a formação, estão: o DF 19 que afirmou “[...] temos cinco disciplinas de didática, e o estágio supervisionado". O DF 20 mencionou "Diante dos comentários dos alunos e levando em consideração a minha disciplina, mesmo que não seja de didática, trabalho com os alunos um pouco de didática voltada para alunos surdos". O DF 21 citou que "Os alunos desenvolvem as suas práticas de ensino, sob a supervisão e orientação de professores habilitados. No entanto, essas experiências não garantem o sucesso na prática didática, pois isso é uma experiência pessoal que se aprimora com o tempo [...]". Já o DF 24 não justificou sua resposta. 
Os DFs 18, 22 e 23 mencionam em suas falas que o conteúdo está posto, garantido aprimoramento. Mas será que existe uma preocupação didática ao ensiná-lo? Até quando vamos nos apoiar na justificativa de que há falhas no processo de implantação das licenciaturas? Que tempo seria necessário para implementar as mudanças? Lembramos que as DCNs foram elaboradas pelo CNE/CP 1/2002 (CONSELHO..., 2002), já sofreram alterações como, por exemplo, a Resolução CNE/CP n. ${ }^{\circ}$ 2/2015 (BRASIL-CNE-CP, 2015), ou seja, temos novas mudanças sendo inseridas nas licenciaturas, quando as anteriores ainda não foram incorporadas pelo corpo de DFs. Entre as mudanças destacamos os núcleos de formação, que resultou na reordenação das disciplinas ofertadas nos cursos de licenciaturas.

Nas turmas e 2010 a 2015, observamos ainda, nas licenciaturas de Ciências da Natureza, uma recorrência na preocupação com o aluno surdo. Isso, provavelmente, se deve ao fato de haver licenciandos surdos nos cursos de licenciatura no IFRO. A demanda do estudante surdo, consciente ou não por parte do DF, evidencia as falhas de comunicação, principalmente se o interprete por algum motivo não comparece à instituição de ensino.

Em se tratando do licenciando surdo, faz-se necessário, por parte do DF, o domínio da organização de aula, a correção de prova que, por vezes, se não contar com a colaboração do interprete, a comunicação torna-se limitada. Essa situação evidencia as fragilidades de conhecimentos por parte do DF com relação ao aluno surdo, diferentemente de outras deficiências, como por exemplo, a deficiência intelectual, cujo o insucesso geralmente é atribuído ao estudante e menos ao docente.

A resposta do DF 21, que diz que "Os alunos desenvolvem as suas práticas de ensino, sob a supervisão e orientação de professores habilitados. No entanto, essas experiências não garantem o sucesso na prática didática, pois isso é uma experiência pessoal que se aprimora com o tempo [...]", indica-nos certa relativização na mesma, pois quem são os professores habilitados que supervisionam a prática de ensino? Não são os próprios Docentes Formadores do curso de licenciatura? O DF 21 sugere haver um terceiro profissional, não demonstrando que também faz parte do corpo de DFs. Entretanto, o referido DF tem razão, a prática educativa se "aprimora com o tempo". Mas é importante não perder de vista que para o licenciando desenvolver cada atividade do curso de licenciatura, ele tem que ser o melhor naquele momento, pois somente aprimoramos o que temos, ninguém melhora o conhecimento que não possui. O que aprimoramos é resultado de algo que fizemos. Portanto, a prática não se "restringe ao fazer, ela se constitui numa 
atividade de reflexão que enriquece a teoria que lhe deu suporte. $\mathrm{O}$ estágio é um processo criador, de investigação, explicação, interpretação e intervenção na realidade" (PIMENTA, 1995, p. 74).

$\mathrm{Na}$ licenciatura em Ciências Biológicas do IFRO campus Ariquemes, também preponderou entre os DFs que o curso assegurou o saber como ensinar, pois $57,1 \%$ (07) Docentes Formadores informaram que a licenciatura garantiu os conhecimentos didáticopedagógicos. Dos 100\% dos DFs (07), 51,1\% justificaram suas respostas sobre o saber como ensinar de forma clara, 28,6\% foram evasivos, $14,3 \%$ não respondeu a questão.

4.2.4 Docentes Formadores do curso de Licenciatura em Física do IFRO do campus de Porto Velho Calama

Dos nove Docentes Formadores (DFs) do campus de Porto Velho Calama, sete (25, 26, 27, 30, 31, 32 e 33) afirmaram que, "sim, o curso garante saber como ensinar" e dois DFs (28 e 29) responderam “em parte”. Os DFs 25 e 28 não justificaram suas afirmativas de garantia do saber como ensinar no curso de licenciatura em Física. Já o DF 26 afirmou que “[...] tanto os conteúdos específicos quanto os pedagógicos ficaram adequados". Para o DF 27, "Em diversos momentos vejo os professores responsáveis pelas disciplinas discutindo e elaborando ações para tanto". O DF 30 relatou que "Todas as áreas específicas do curso têm sua correspondente didática para os alunos montarem sua relação". O DF 31 observou que "[...] devido os professores desenvolverem atividades didáticas, exposição dos conteúdos e regência em sala [...]". Para o DF 32, "Essa se trata de uma parte específica do seu ensino" e o DF 33 fundamentou sua justificativa na "Qualificação".

O DF 29 afirmou que os conhecimentos a respeito do saber como ensinar foram garantidos em parte, pois compreende que percebe "[...] que falta aprofundar em alguns aspectos. Ex: Metodologias de ensino da física ${ }^{6}$ [sic]; Recursos didáticos para o ensino da física [sic]; Estratégias didáticas para o ensino de física [sic] o que implicaria em dividir com o professor pedagogo a responsabilidade por esses aspectos da formação. Muitos professores acreditam que a formação pedagógica é responsabilidade do pedagogo e isso é um grande equívoco, pois não compreendem que pedagogo não detém os conhecimentos

\footnotetext{
${ }^{6}$ A ênfase dos grifos foi realizada pelo Docente Formador no ato da resposta ao questionário misto.
} 
específicos da formação desse futuro professor, precisando, portanto, de um trabalho de parceria".

Destacamos a resposta do DF 27, que observa que "Em diversos momentos vejo os professores responsáveis pelas disciplinas discutindo e elaborando ações para tanto". Este registro na resposta do referido DF sugere-nos à atribuição de exclusiva responsabilidade, para os DFs, que lecionam as disciplinas didático-pedagógicas no curso de licenciatura em Física. No entanto, cabe salientar que a responsabilidade é de todos os DFs, no âmbito das disciplinas que ministram, o desenvolvimento do trabalho de formação do professor, pois a maioria das disciplinas tem uma carga horária destinada, exclusivamente, para a Prática Como Componente Curricular. Assim, questionamos: Como tem sido trabalhada a carga horária de cada disciplina? Será que está tão distante do que é proposto das DCNs?

No registro do DF 30, há indicações que primeiro aprendemos o conteúdo, depois aprendemos como ensinar o conteúdo. Falta ainda para o licenciando compreender como de fato acontece o ensino. O ideal constitui-se na teorização, no ensino, no fazer, na reelaboração, na reorganização do conteúdo desenvolvido. Há um entendimento que compete aos DFs da área pedagógica, isto é, formar o licenciando para ser professor, mas compete aos DFs de todas-às as áreas do conhecimento a formação para a docência, independentemente de quais disciplinas o Docente Formador ministra.

A resposta do DF 29 sugere-nos algo que se constitui procedente para todas as licenciaturas de Ciências da Natureza, uma vez que afirma que sozinho o professor da área didático-pedagógica não forma professor, assim como o professor das outras áreas do conhecimento também não consegue formar o professor somente por meio de sua disciplina e propõe fazer a formação conjunta, não dividir o trabalho. Tal entendimento condiz com Pimenta e Anastasiou (2010, p. 37-38) quando salientam “[...] a importância da preparação no campo específico e no campo pedagógico [...]”, nos cursos de formação inicial de professores.

A resposta do DF 29 está em consonância com a ideia de Queiroz, de Barbosa-Lima e de Castro (2002, p. 2), pois eles entendem que "um bom conhecimento de Ciência já não é assim considerado suficiente, chegando a ser minimizado em alguns contextos", principalmente, agora em tempos em que informação está disponível.

É um grande equívoco atribuir exclusivamente aos pedagogos a responsabilidade de assegurar a didática do como ensinar, visto que esta não pode ser realizada em 
distanciamento das outras áreas previstas na matriz curricular. O DF 29 revela a necessidade de conciliar os esforços de integralização de conhecimentos para formar professor. Ele propõe compartilhar formação docente.

No curso de licenciatura em Física do IFRO campus Porto Velho Calama, 77,7\% (09) Docentes Formadores afirmaram que o curso assegurou o saber como ensinar. Dos $100 \%$ dos DFs (09), 55,5\% justificaram suas respostas sobre o referido conhecimento claramente, $22,3 \%$ foram evasivos, $11,1 \%$ forma evasivos e $11,1 \%$ atribuiu ao pedagogo a incumbência deste saber.

Em síntese, entre os DFs, tivemos $72,7 \%$ que afirmaram que os cursos de licenciatura em Ciências Biológicas do IFRO "garantiu o saber como ensinar" e 27,3\%, mencionaram, "em parte". Todavia, as justificativas referente a garantia do saber como ensinar predominou clareza, de tal conhecimento, entre os Docentes Formadores dos cursos de licenciatura em Física do campus Calama e Ciências Biológicas do campus Ariquemes, respectivamente, cinco, de nove DFs e quatro, de sete Docentes Formadores.

\subsection{A visão dos professores egressos a respeito do saber o que ensinar nas licenciaturas em Ciências da Natureza do IFRO}

Foram cinco os Professores Egressos (PEs) entrevistados, sendo um do campus de Colorado do Oeste, três do campus Ji-Paraná e um do campus Ariquemes. O PE do campus Porto Velho Calama optou por não participar da pesquisa, pois tencionava deixar a profissão de professor tão logo concluísse outro curso superior na área de engenharia.

Para garantir o anonimato a esses participantes da pesquisa com relação ao saber como ensinar, adotamos o mesmo procedimento seguido para os DFs, na subseção 4.2, isto é, utilização de números. Sendo assim, os PEs são aqui identificados com um número de 01 a 04 - PE 01, PE 02, PE 03 e PE 04.

O Professor Egresso do curso de licenciatura de Ciências Biológicas do campus de Colorado do Oeste, PE 01, afirmou que: “Os conhecimentos didáticos da licenciatura foram fundamentais para direcionar os conteúdos que trabalho. Por exemplo, em geologia a gente trabalha a parte de solo, tem muita proximidade ao conteúdo do sexto ano, que é planeta, então construí um vulcão". O PE 01 demonstra que a integração dos conhecimentos didático- pedagógicos e específicos são elementos essenciais no exercício de sua docência, 
inclusive consegue evidenciar de forma efetiva que aquele conhecimento estudado no curso de licenciatura está vinculado aos conhecimentos da Educação Básica, reconhecendo o quão importante são os conhecimentos didáticos, ou seja, evidenciou o saber como (didáticopedagógico), no processo de ensino do conhecimento específico (saber o que ensinar).

$\mathrm{Na}$ fala do Professor Egresso ficou explicito o quanto a didática é importante como disciplina na sua formação. A formação dos Docentes Formadores que têm licenciatura também contou com o conhecimento didático. Será que todos os Docentes Formadores têm essa consciência ao estabelecer a relação entre o que ele ensina com o que os Professores Egressos ensinarão na Educação Básica, da maneira que o PE 01 conseguiu perceber, relacionar e desenvolver?

Dos três PEs da licenciatura em Química, do campus Ji-Paraná, dois, os PEs 02 e 04 afirmaram que o curso garantiu dos conhecimentos relativos ao saber como ensinar, e um respondeu em parte. As justificativas dos PEs que mencionaram a garantia do referido saber foram: DF 02 "Tivemos muitos exercícios desde os mais simples aos mais complexos e são possíveis de serem utilizados na sala de aula da educação básica” O PE 04 declarou "[...]os professores da didática passaram da melhor forma possível. Mesmo não sendo uma disciplina tão dura quanto as específicas, mas contavam suas experiências da rede estadual". O PE 03 que respondeu "em parte”, justificou “[...] faltou objetividade e clareza para trabalhar as didáticas referentes à química que têm maior resultado sobre a aprendizagem do aluno".

Os PEs 02 e 04, do curso de licenciatura em Química, reconhecem como foram encaminhadas as disciplinas didático-pedagógicas e as relacionam com a importância destes saberes na Educação Básica. Isso condiz com a DCN (BRASIL, 2002), inclusive com o Instrumento do Sistema Nacional de Avaliação da Educação Superior - SINAES (BRASIL, 2004), que na avaliação dos cursos de licenciatura o item 1.22 se refere a "Integração com as redes públicas de ensino" (MEC, 2015, p. 15), obrigatório para os cursos de formação inicial de professores.

Outro dado a ser considerado na resposta dos PEs 02 e 04 está apresentado no relatório de avaliação de reconhecimento do curso de licenciatura em Química, ou seja, "[...] $50 \%$ do corpo docente tem pelo menos três anos de experiência na educação básica" (IFRO, 2014, p. 12), item também avaliado pelo Instituto Nacional de Estudos e Pesquisas 
Educacionais Anísio Teixeira (INEP) para composição do conceito de curso e que pode ter possibilitado maior contribuição na formação dos acadêmicos.

No entanto, o PE 03 registra acerca das limitações da didática, especificamente, destinadas aos conteúdos pertinentes à química, pois é necessário reconhecer que cada ciência apresenta determinadas particularidades que, em determinados momentos do processo de ensino, são necessárias levar em consideração. Aqui cabe uma pergunta será que desde o início do curso foi considerada essa especificidade apontada pela PE?

O PE 05, do curso de licenciatura em Ciências Biológicas, do campus Ariquemes, respondeu "sim" quanto à garantia do saber como ensinar, que versa sobre o conhecimento didático-pedagógico, porém não justificou sua resposta.

Em resumo, dos cinco PEs participantes da pesquisa, quatro afirmaram que "o curso de licenciatura na área de Ciências da Natureza garantiu saber como ensinar", um registrou "em parte" e quatro apresentaram justificativas diretamente vinculadas ao referido saber.

\section{CONSIDERAÇÕES}

Nos cursos de licenciaturas em Ciências da Natureza do IFRO, o saber como ensinar demanda ampliar a vinculação das práticas pedagógicas desenvolvidas nos espaços escolares, pois é escola o lugar que capaz de promover a interligação com os anseios sociais e às necessidades oriundas do enredamento do ambiente educativo formal. É verdadeiro, que esse lugar se institui um instrumento respeitável para a formação de um professor e, ao mesmo tempo, para o sucesso do aluno, no decorrer de sua escolarização.

Nesse contexto, por meio da pesquisa efetivada a partir dos PPCs das licenciaturas em Ciências Biológicas, Química e Física do IFRO, verificamos a necessidade de uma articulação entre teoria e prática, no que se refere às disciplinas pertinentes ao saber o que ensinar nesses cursos.

Com relação à visão dos DFs quanto à garantia do saber como ensinar na licenciatura em Ciências Biológicas do campus de Colorado do Oeste e licenciatura em Química do IFRO do campus Ji-Paraná, embora a maioria dos DFs afirme que o curso, o assegurou o referido saber, a minoria dos Docentes Formadores, em suas justificativas, apresenta clareza no que se refere ao saber. 
$\mathrm{Na}$ visão dos DFs da licenciatura em Ciências Biológicas, campus Ariquemes e na licenciatura em Física, campus de Porto Velho Calama, em que predominou entre os DFs que ambos cursos do IFRO garantiram o saber como ensinar, em suas justificativas, demonstraram compreensão no que diz respeito ao referido saber.

Em síntese, nas licenciaturas em Ciências da Natureza ofertado pelo IFRO no período de (2010-1 a 2015-2), dos trinta e três (33), Docentes Formadores que lecionaram nos cursos e participaram da pesquisa, $72,7 \%$ (24) DFs afirmaram que os cursos de licenciaturas de Ciências Biológicas, Física e Química garantiram o saber como ensinar. Em suas justificativas 39,4\% (13) DFs demonstraram clareza no que tange ao saber como ensinar, 27,3\% (09) DFs as justificativas foram evasivas, 24,3\% (08) não justificaram e 9\% (03) atribuíram aos docentes licenciados em pedagogia a responsabilidade de ensinar os conhecimentos didático-pedagógicos aos licenciandos.

Dos cinco Professores Egressos dos cursos de licenciaturas em Ciências Biológicas, Química e Física, quatro, isto é, $80 \%$ dos participantes da pesquisa afirmaram que a formação inicial de professores, ofertada pelo IFRO, "assegura o saber como ensinar totalmente" e um, ou seja, 20\% dos PEs respondeu que o IFRO assegura "parcialmente" o referido saber. Entre os quatro PEs que reconhecem a totalidade da garantia do saber em tela um explicitou claramente a da conexão dos saberes didático-pedagógicos para a docência, assim como a correlação dos conteúdos com a Educação Básica. No que diz respeito ao PE que reconhece a garantia parcial do referido saber, cabe salientar, que este o faz, em relação à carência de procedimentos didático-pedagógicos destinados, particularmente, a área de química, o que é admissível, pois cada ciência tem seus métodos.

\section{REFERÊNCIAS}

AMARAL, Edson Toledo do. O professor de ensino médio e o seu olhar sobre a leitura e a escrita em sua disciplina. 2010. Dissertação (Mestrado). Universidade Metodista de Piracicaba. Faculdade Ciências Humanas. Programa de Pós-Graduação em Educação, Piracicaba, 2010. Disponível em: http://iepapp.unimep.br/biblioteca_digital/pdfs/docs/10032011_115919_dissertacao.pdf. Acesso em: 14 jun. 2021.

BARDIN, L. Análise de conteúdo. Tradução: L. de A. Rego e A. Pinheiro. Lisboa: Edições 70, 2006. (Obra original publicada em 1977).

BARDIN, L. Análise de conteúdo. 6. ed: São Paulo: Edições 70, 2011. 
BARDIN, L. Análise de conteúdo. Edições revista e ampliada. São Paulo: Edições 70, 2016.

BARBOSA, Edson Pereira. Leituras sobre o processo de implantação de uma licenciatura em ciências naturais e matemática por área de conhecimento. 2012. 311f. Tese (Doutorado) - Instituto de Geociências e Ciências Exatas, Universidade Estadual Paulista. Rio Claro, 2012. Disponível em:

https://repositorio.unesp.br/bitstream/handle/11449/102116/barbosa_ep_dr_rcla.pdf;sequenc $\underline{\mathrm{e}=1}$. Acesso em: 14 jun. 2021.

BRASIL.CONSELHO NACIONAL DE EDUCAÇÃO. Conselho Pleno. Resolução no 2, de $1^{\circ}$ de julho de 2015. Define as Diretrizes Curriculares Nacionais para a formação inicial em nível superior (cursos de licenciatura, cursos de formação pedagógica para graduados e cursos de segunda licenciatura) e para a formação continuada. Disponível em: http://portal.mec.gov.br/docman/agosto-2017-pdf/70431-res-cne-cp-002-03072015-pdf/file. Acesso em: 14 jun. 2021.

BRASIL. Lei $\mathbf{n}^{0}$ 10.861, de 14 de abril de 2004. Institui o Sistema Nacional de Avaliação da Educação Superior - SINAES. 2004. Disponível em: http://www.planalto.gov.br/ccivil_03/_ato2004-2006/2004/lei/110.861.htm. Acesso em: 13 jun. 2021.

CONSELHO NACIONAL DE EDUCAÇÃO. Conselho Pleno. Resolução no $\mathbf{2}$, de 19 de fevereiro de 2002a. Institui a duração e a carga horária dos cursos de licenciatura, de graduação plena, de formação de professores da Educação Básica em nível superior. Disponível em: http://portal.mec.gov.br/cne/arquivos/pdf/CP022002.pdf. Acesso em: 14 jun. 2021.

CONSELHO NACIONAL DE EDUCAÇÃO. Conselho Pleno. Resolução n. ${ }^{\circ} \mathbf{1}$, de 18 de fevereiro de 2002. Institui Diretrizes Curriculares Nacionais para a Formação de Professores da Educação Básica, em nível superior, curso de licenciatura, de graduação plena. Disponível em: http://portal.mec.gov.br/cne/arquivos/pdf/rcp01_02.pdf. Acesso em: 14 jun. 2021.

FLICK, Uwe. Introdução à Pesquisa Qualitativa. $3^{\text {a }}$ ed. Tradução: COSTA, J. E. Porto Alegre: Artmed, 2009.

GASPAR, Maria de Lourdes Ribeiro. O Programa Institucional de Bolsas de Iniciação à Docência (PIBID): as repercussões nas perspectivas de seus atores. 354 f. 2017. Tese (Doutorado) - Universidade Federal de Minas Gerais. Faculdade de Educação. Belo Horizonte. MG. 2017. Disponível em: https://repositorio.ufmg.br/handle/1843/BUBDAW9KNP. Acesso em: 14 jun. 2021.

GARCÍA, Carlos Marcelo. Formación del professorado para el cambio educativo. $2^{\mathrm{a}}$ ed. Barcelona: Espanã. Editora EUB. 1995.

GIL, Antonio Carlos. Como elaborar projetos de pesquisa. 5a ed. São Paulo: Atlas, 2010. 
GIL, Antônio Carlos. Métodos e técnicas de pesquisa social. 7ª ed. São Paulo: Atlas, 2019.

GATTI, Bernadete Angelina; NUNES Marina Muniz Rossa. Formação de professores para o ensino fundamental: estudo de currículos das licenciaturas em pedagogia, língua portuguesa, matemática e ciências biológicas. São Paulo: FCC/DPE, 2009. Disponível em: http://tiny.cc/gsllgz. Acesso em: 12 jun. 2021.

GAUTHIER, Clermont et al. Por uma teoria da Pedagogia. Ijuí: Unijuí, 1998;

GAUTHIER, Clermont et al. Por uma teoria da pedagogia: pesquisas contemporâneas sobre o saber docente. $2^{\text {a }}$ ed. Ijuí: Editora Unijuí, 2006.

IMBERNÓN, Francisco Ernani Rosa. Formação Docente e profissional: formar-se para a mudança e a incerteza. Tradução: Silvana Cobucci Leite. 9a ed. São Paulo: Cortez, 2011.

INSTITUTO FEDERAL DE EDUCAÇÃO, CIÊNCIA E TECNOLOGIA DE RONDÔNIA. Relatório do Curso de Licenciatura em Química - e-mec 2014. Brasília: e-mec, 2014.

INSTITUTO FEDERAL DE EDUCAÇÃO, CIÊNCIA E TECNOLOGIA DE RONDÔNIA. Resolução n. ${ }^{\circ}$ 5/CONSUP/IFRO, de 12 de março de 2012. Dispõe sobre o Projeto Pedagógico do Curso de Licenciatura em Física, do Instituto Federal de Educação, Ciência e Tecnologia de Rondônia - Campus Porto Velho Calama. Disponível em: https://bit.ly/2CTywWO. Acesso em: 16 fev. 2021.

INSTITUTO FEDERAL DE EDUCAÇÃO, CIÊNCIA E TECNOLOGIA DE RONDÔNIA. Resolução n. ${ }^{\circ}$ 7/CONSUP/IFRO, de 12 de março de 2012b. Dispõe sobre o Projeto Pedagógico do Curso de Licenciatura em Ciências Biológicas, do Instituto Federal de Educação, Ciência e Tecnologia de Rondônia - Campus Ariquemes. Disponível em: https://bit.ly/2D3DO1S. Acesso em: 16 fev. 2021.

INSTITUTO FEDERAL DE EDUCAÇÃO, CIÊNCIA E TECNOLOGIA DE RONDÔNIA. Resolução n. ${ }^{\circ}$ 8/CONSUP/IFRO, de 12 de março de 2012c. Dispõe sobre o Projeto Pedagógico do Curso de Licenciatura em Ciências Biológicas, do Instituto Federal de Educação, Ciência e Tecnologia de Rondônia - Campus Colorado do Oeste. Disponível em: https://bit.ly/35iUzCk. Acesso em: 16 fev. 2021.

INSTITUTO FEDERAL DE EDUCAÇÃO, CIÊNCIA E TECNOLOGIA DE RONDÔNIA. Resolução n. ${ }^{\circ}$ 6, de 14 de dezembro de 2009. Dispõe sobre o Projeto Pedagógico do Curso de Licenciatura em Química, do Instituto Federal de Educação, Ciência e Tecnologia de Rondônia - Campus Ji-Paraná. Aprovado Ad referendum. Coordenação de Licenciatura. Colorado do Oeste.

LAPLANE, Adriana. Lia. Friszman de. Notas para uma análise dos discursos sobre inclusão escolar. In: GÓES, Maria Cecília Rafael de.; LAPLANE, A.L.F. (org.). Políticas e práticas de educação inclusiva. Campinas: Autores Associados, 2004, p. 5-20.

LIBÂNEO, José. Carlos. Didática. $2^{\mathrm{a}}$ ed. São Paulo: Cortez, 2013. 
LIBÂNEO, José Carlos. Diretrizes curriculares da pedagogia: imprecisões teóricas e concepção estreita da formação profissional de educadores. Educ. Soc. Campinas, v. 27, n. 96,2006. https://www.scielo.br/j/es/a/mSLjpLJDzBytgc6t6VcsxYf/abstract/?lang=pt. Acesso em: 14 jun. 2021.

MARCELO, Carlos. A identidade docente: constantes e desafios. Revista Formação Docente, Belo Horizonte, v. 01, n. ${ }^{\circ}$ 01, p. 109-131, ago./dez. 2009. Disponível em: http://formacaodocente.autenticaeditora.com.br/artigo/exibir/1/3/1. Acesso em: 12 jun. 2021.

MARCELO, Garcia Carlos. El professorado principiante: insercion a la docência. España, Editora: OCTAEDRO, 2009.

MANTOAN, Maria Teresa Eglér. Inclusão Escolar O que é? Por quê? Como Fazer?. São Paulo: Summus, 2017.

MEC. Instrumento de Avaliação de Cursos de Graduação presencial e a distância. 2015. Disponível em: http://inep.gov.br/instrumentos. Acesso em: 10 jun. 2020.

NÓVOA, António. Formação de professores e profissão docente. In: NÓVOA, A. (Coord.). Os professores e a sua formação. Lisboa: Dom Quixote/IIE, 1997, p.15-33;

ORGANIZAÇÃO PARA A COOPERAÇÃO E DESENVOLVIMENTO ECONÔMICO. Brasil ocupa $60^{a}$ posição em ranking de educação em lista com 72 países. 2015. Disponível em: https://www.oecd.org/pisa/PISA-2015-Brazil-PRT.pdf. Acesso em: 11 mai. 2021.

PIMENTA, Selma Garrido. Formação de professores: identidade e saberes da docência. In: PIMENTA, Selma Garrido. (Org). Saberes pedagógicos e atividade docente. São Paulo: Cortez Editora, 1999. (p. 15-34).

PIMENTA, Selma Garrido. O pedagogo na Escola Pública. São Paulo: Edições Loyola, 1995.

PIMENTA, Selma Garrido; ANASTASIOU, Léa das Graças Camargo. Docência no Ensino Superior. $4^{\mathrm{a}}$ ed. São Paulo: Cortez, 2010.

QUEIROZ, Glória Regina Pessôa Campello; BARBOSA LIMA, Maria da Conceição; CASTRO, Giselle Faur de. Uma visão da formação inicial de professores de física da última virada do século no Brasil. IF-UERJ, 2002.

SHULMAN, Lee. Conhecimento e ensino: fundamentos para a nova reforma. Cadernos Cenpec, $\quad$ v. $4, \quad$ n. $^{{ }^{-}}$2, 2014. Disponível em: http://cadernos.cenpec.org.br/cadernos/index.php/cadernos/article/view/293. Acesso em: 11 mai. 2021;

SHULMAN, Lee. Those who understand: knowledge growth in teaching. Educational Researcher, v. 15, n. ${ }^{\circ}$ 2, fev. 1986, p. 4-14. Disponível em: 
http://www.fisica.uniud.it/URDF/masterDidSciUD/materiali/pdf/Shulman_1986.pdf. Acesso em: 15 fev. 2021.

SILVA, Carla Odete Balestro. Análise da atividade do docente de informática que atua na educação profisssional dos institutos federais de educação, ciência e tecnologia. 2016. 317 f. Tese (Doutorado) - Universidade Federal do Rio Grande do Sul. Faculdade de Educação. Programa de Pós-Graduação em Educação. Porto Alegre, BR-RS, 2016. Disponível em: https://www.lume.ufrgs.br/handle/10183/153012. Acesso em: 15 fev. 2021.

TARDIF, Maurice. Saberes docentes e formação profissional. $2^{\mathrm{a}}$ ed. Petrópolis: Vozes, 2002.

\section{APÊNDICE}

\section{AGRADECIMENTOS}

Agradecemos ao Instituto Federal de Educação Ciências e Tecnologia de Rondônia (IFRO) pela parceria com a Rede Amazônica de Educação em Ciências e Matemática, polo da Universidade Federal de Mato Grosso, por meio dos quais tornaram realidade o meu doutoramento.

Agradecemos aos docentes e egressos dos cursos de Licenciatura em Ciências da Natureza do IFRO pelas significativas contribuições a nossa pesquisa.

\section{FINANCIAMENTO}

O presente trabalho foi realizado com apoio do Conselho Nacional de Desenvolvimento Científico e Tecnológico (CNPq) - Brasil e pela a Fundação de Amparo ao Desenvolvimento das Ações Cientificas e Tecnológicas e à Pesquisa (FAPERO) - Rondônia.

\section{CONTRIBUIÇÕES DE AUTORIA}

Resumo/Abstract/Resumen: Maranei Rohers Penha e Marta Maria Pontin Darsie.

Introdução: Maranei Rohers Penha e Marta Maria Pontin Darsie.

Referencial teórico: Maranei Rohers Penha e Marta Maria Pontin Darsie.

Análise de dados: Maranei Rohers Penha e Marta Maria Pontin Darsie.

Discussão dos resultados: Maranei Rohers Penha e Marta Maria Pontin Darsie.

Conclusão e considerações finais: Maranei Rohers Penha e Marta Maria Pontin Darsie.

Referências: Maranei Rohers Penha e Marta Maria Pontin Darsie.

Revisão do manuscrito: Eduardo Freire Ribeiro.

Aprovação da versão final publicada: Maranei Rohers Penha e Marta Maria Pontin Darsie.

\section{CONFLITOS DE INTERESSE}

Os autores declararam não haver nenhum conflito de interesse de ordem pessoal, comercial, acadêmico, político e financeiro referente a este manuscrito.

\section{DISPONIBILIDADE DE DADOS DE PESQUISA}

O conjunto de dados que dá suporte aos resultados da pesquisa foi publicado no próprio artigo.

\section{CONSENTIMENTO DE USO DE IMAGEM}

Não se aplica.

\section{APROVAÇÃO DE COMITÊ DE ÉTICA EM PESQUISA}

A presente pesquisa foi aprovada por Comitê de Ética em Pesquisa com seres humanos (CAAE 61713816.3.0000.5653). 
COMO CITAR - ABNT

PENHA, Maranei Rohers. DARSIE, Marta Maria Pontin. O Saber como Ensinar nas Licenciaturas em Ciências da Natureza do Instituto Federal de Educação, Ciência e Tecnologia de Rondônia (IFRO). REAMEC - Rede Amazônica de Educação em Ciências e Matemática. Cuiabá, 9. n. 3. e21096, set./dez., 2021. https://doi.org/10.26571/reamec.v9i3.12618.

\section{COMO CITAR - APA}

Penha, M.R. \& Darsie, M.M.P. (2021). O Saber como Ensinar nas Licenciaturas em Ciências da Natureza do Instituto Federal de Educação, Ciência e Tecnologia de Rondônia (IFRO). REAMEC - Rede Amazônica de Educação em Ciências e Matemática, 9(3), e21096. https://doi.org/10.26571/reamec.v9i3.12618.

\section{LICENÇA DE USO}

Licenciado sob a Licença Creative Commons Attribution-NonCommercial 4.0 International (CC BY-NC 4.0). Esta licença permite compartilhar, copiar, redistribuir o manuscrito em qualquer meio ou formato. Além disso, permite adaptar, remixar, transformar e construir sobre o material, desde que seja atribuído o devido crédito de autoria e publicação inicial neste periódico.

\section{DIREITOS AUTORAIS}

Os direitos autorais são mantidos pelos autores, os quais concedem à Revista REAMEC - Rede Amazônica de Educação em Ciências e Matemática - os direitos exclusivos de primeira publicação. Os autores não serão remunerados pela publicação de trabalhos neste periódico. Os autores têm autorização para assumir contratos adicionais separadamente, para distribuição não exclusiva da versão do trabalho publicada neste periódico (ex.: publicar em repositório institucional, em site pessoal, publicar uma tradução, ou como capítulo de livro), com reconhecimento de autoria e publicação inicial neste periódico. Os editores da Revista têm o direito de proceder a ajustes textuais e de adequação às normas da publicação.

\section{PUBLISHER}

Universidade Federal de Mato Grosso. Programa de Pós-graduação em Educação em Ciências e Matemática (PPGECEM) da Rede Amazônica de Educação em Ciências e Matemática (REAMEC). Publicação no Portal de Periódicos UFMT. As ideias expressadas neste artigo são de responsabilidade de seus autores, não representando, necessariamente, a opinião dos editores ou da referida universidade.

\section{EDITOR}

Patrícia Rosinke (iD) (9)

\section{HISTÓRICO}

Submetido: 16 de junho de 2021.

Aprovado: 25 de setembro de 2021.

Publicado: 27 de novembro de 2021. 